\title{
A review of approaches for resolving disputes between physicians and families on end-of-life care for newborns
}

\author{
Brian M. Cummings $\mathbb{D}^{1} \cdot$ Mark R. Mercurio ${ }^{2} \cdot$ John J. Paris ${ }^{3,4}$
}

Received: 25 October 2019 / Revised: 27 March 2020 / Accepted: 24 April 2020 / Published online: 11 May 2020

(c) Springer Nature America, Inc. 2020

\section{Introduction}

In a commentary in the New England Journal of Medicine (NEJM) on a ruling of the Texas Supreme Court in Miller v. $H C A$ [1], George Annas, the NEJM legal analyst, observed, "One bioethical issue is as intractable today as 30 years ago when the topic was first publicly discussed: the extent of parental authority to refuse life-sustaining medical treatment for an extremely premature infant" [2]. The case involved the resuscitation of a 23-week $615 \mathrm{~g}$ infant over parental objections. It took years to resolve the case in the legal system. Nearly two decades later, we might inquire whether neonatologists and other critical care practitioners have greater comfort in dealing with the issue of parental objection?

Looking for guidance in the American legal community is not particularly enlightening. Left unresolved in physician-parent conflicts are such issues as who decides and on what standard? Societal norms over the past half a century on who is to make treatment decisions, and on what standard, have shifted [3]. It is now agreed within the bioethical and medical communities in the United States that where the risk of mortality is significant and the prospect of benefit to an infant is suffused in ambiguity and uncertainty, the decision on whether or not to initiate

Brian M. Cummings

bmcummings@mgh.harvard.edu

Mark R. Mercurio mark.mercurio@yale.edu

$\triangle$ John J. Paris

john.paris@bc.edu

1 Department of Pediatrics, Massachusetts General Hospital, Harvard Medical School, Boston, MA 02114, USA

2 Yale School of Medicine, New Haven, CT 06504, USA

3 Boston College, Chestnut Hill, MA 02167, USA

4 Present address: St. Joseph's University, Philadelphia, PA, USA treatment belongs to the parents. That position is best summarized in the American Academy of Pediatrics (AAP) guidelines on "Nonintervention or Withdrawal of Intensive Care for High Risk Newborns," published in 2007 and reaffirmed in 2015. We find the AAP's position spelled out in three brief statements:

(1) When early death is very likely and survival would be accompanied by high risk of unacceptably severe morbidity, intensive care is not indicated.

(2) When survival is likely and risk of unacceptably severe morbidity is low, intensive care is indicated.

(3) There may be cases that fall [outside] these first two categories...parental desires should determine the treatment approach [4].

Although the term "unacceptably severe" is ambiguous and allows for considerable "wiggle room," the AAP guidelines mark a decided shift from the tradition that medical treatment decisions are the domain of the physician. That standard prevailed from the dawn of medicine until Kubler-Ross' landmark 1969 book On Death and Dying [5]. Her contribution to bioethics was not only psychological insight into the stages of dying, but also her insistence that physicians listen to the voices and values of dying patients. With the AAP guidelines as our starting point and left to our own individual practices, how do providers build trust between clinicians and families?

\section{Is "futility" a helpful framework?}

Futility is not a helpful terminology for families or providers. Paul Helft et al.' article on "The Rise and Fall of the Futility Movement" [6] established that for nearly a decade in the 1980s and 1990s the concept of "medical futility" was an important aspect in the resolution of physician-family conflicts. Its significance faded when it became clear that there was no agreement in the medical community or 
society in general on the meaning of the term. The focus shifted to the importance of so-called "family autonomy." The prolonged debate on autonomy was first raised in a 1914 opinion by Justice Benjamin Cardozo of the New York Court of Appeals in Schloendorff v. Society of the New York Hospital [7]. In that case, the state's court of final jurisdiction ruled that the term "autonomy" should be confined to the value choices of a competent adult patient. Subsequently, New York's highest court recognized the validity of proxy assessment for the nondecisionally capable patient's wishes as well as the known values of the once competent adult [8]. "Best interest" of the patient, not the determination of a family's values, emerged as the standard for minors and those who never possessed decision-making capacity. That standard is articulated in the AAP's 2007 guidelines on decision-making for newborns, as well as for infants and children [9].

\section{Should clinicians' judgments to intervene prevail?}

A decided shift in the right of parents to make medical decisions for their child born with a severely compromised medical condition occurred in a 1974 legal case entitled, Maine Medical Center v. Baby Boy Houle [10]. The child, Sidney Houle, was born with multiple medical problems. Her parents and treating physician agreed to forego invasive surgical treatment. Some at Maine Medical Center objected. They brought suit in Maine Superior Court. There Judge David Roberts began his analysis of the case by stating "While there may be some doubt about the rights of the unborn child, once born the most basic right enjoyed by every human being is the right to life itself." Judge Roberts ruled that if a patient has medical needs and a medically feasible response is available that intervention must be utilized regardless of the patient's future quality of life. The surgery was performed. Sidney died soon thereafter.

The court's "life-at-any cost" ruling occasioned a criticism in a 1974 JAMA article by McCormick entitled, "To Save or Let Die?" [11]. McCormick asked, "Granted the life can be saved, what kind of a life are we saving?" He went on to note that there was no moral obligation to impose treatment on a dying patient or one who is totally dependent on medical measures to sustain life. Nor is there an obligation to do so for a patient whose potential for relationships never existed or is exhausted. His final point on the fundamental importance of "relationships" was McCormick's major contribution to the topic. His article has since become a landmark in medical ethics, one cited with approval by nearly every professional group that has attempted to design standards for end-of-life care [12].

\section{Should judgments be left to parental discretion?}

A year earlier than McCormick's commentary on aggressive interventions, Duff and Campbell's article in the NEJM brought the topic of ethical dilemmas in the newborn nursery to the public's attention [13]. The authors reported that of 299 deaths in the special care nursery at Yale New Haven Hospital between 1970 and 1972, 43 (14\%) were associated with discontinuation of medical treatment. If the parents and physicians agreed that prognosis for "meaningful life" was extremely poor for a child born with multiple abnormalities, trisomy, cardiopulmonary crippling, or a central nervous system disorder, often no further treatment was provided.

In those authors' perspective the decision to withhold or withdraw treatment belonged to those who bore the responsibility for the consequences of the decision-the family. In a subsequent article Paris and McCormick criticized that approach as "normless" [14]. It provided no guidelines, no standards, no norms other than the wishes of the parents on which to decide whether to withhold or withdraw medical treatment. Under that schema a decision could equally well be based on a concern for "family convenience" as on the "best interests" of the child. What their approach failed to understand is that even good, caring, loving parents-acting out of fear, ignorance or a misreading of the clinical situation-can and do make choices antithetical to the child's interests [15]. Physicians, as seen in the well-known Stinson case [16], can also err in their judgments on the value of medical interventions for a seriously compromised newborn.

\section{Different approaches of the United Kingdom and the United States courts}

The changes in standards and norms on medical decisionmaking are observable in the different approaches to decision-making on end-of-life cases in British and American courts [17]. Although both share the common law tradition, the way courts in those countries decide cases is different. In the English tradition, if one party in a family-physician conflict seeks judicial resolution, the court - and the court alone-will determine the "best interests" of the patient. The arguments of the physicians and the family will be heard and considered. The rationale provided by either side, however, is not dispositive.

Clear guidelines have been formulated by the courts in the United Kingdom that the decision is to be based not on the personal predilections of the judge, physician, or family, but on an independent assessment by the court of the "best interests" of the patient. The decision is not necessarily what the judge would personally choose. Nor is it to be based on 
what the judge believes is the stronger argument. The assessment in the English system is to be made exclusively on the court's judgment of the patient's "best interests." That standard is far different from the tradition of "the doctor knows best" that prevailed from the dawn of medicine through the mid-twentieth century in the United States and the United Kingdom. That older standard continues to this day in much of the non-Anglo-Saxon world.

In the United States, years of legal wrangling are a norm. The case of Terri Schiavo is illustrative of this reality. The dispute among the family on who should decide went to a Florida trial court, the Florida Court of Appeals, Florida's Supreme Court, a Federal District Court, a Federal Circuit Court of Appeals, and the United States Supreme Court. The case also involved the Florida Legislature, the Governor of Florida, the United States Congress, and the President of the United States, with further commentary from Italian Parliament, the Vatican, and the Pope. All were, at one time, involved in this dispute on medical decisionmaking [18]. The Schiavo case, as did the British cases of Charlie Gard and Alfie Evans, demonstrated that the public and the media can be highly vocal, influential, and militant advocates for a particular position on end-of-life medical decision-making. Such intrusions make the role of bedside caregivers ever more difficult [19].

\section{The preferred approach to resolution of physician-family conflict: shared decision- making}

Rather than litigation or seeking third party resolution, John Lantos in the NEJM recently summarizes todays generally accepted approach of shared decision-making by the physician and family as the preferred solution [20]. Listening to the patient's family and assisting them in meeting their goals has proven successful in resolving what can seem to be intractable parent-physician conflict. The potential for conflict between parents and physicians, however, has not been fully resolved, nor is it easily dissipated [21, 22]. How can we best implement shared decision-making in the clinical setting?

Recent studies provide an important context for physicians navigating the complexity of building trust and incorporating parental values in difficult decisions. Families want to be involved. In a study recently published in this journal, parents of NICU patients were surveyed on their decision-making as well as their regret at the decisions that were made during their child's NICU stay [23]. The vast majority of parents preferred active or shared decisionmaking. They wanted to be involved in critical decisions. Most importantly, being involved was associated with less parental regret.
One potential barrier to shared decision-making is a perception that parents could impede clinician autonomy on medical decisions. Clinicians do not want to have to get into the weeds for everything. A recent study refutes this concern and does not show parents want to undermine a physician's professional expertise [24]. In this study of 136 NICU parents, parents reported preferences to defer to caregivers for decisions that were technical in nature, that had high potential for benefit, that required medical expertise or where urgent. Parents, however, wanted to be involved when "big picture" goals or when significant risks were at stake. They believe their values and choices should be seriously considered in these matters and gives providers clear guidance on what is the ideal scope of shared decision-making.

From the provider perspective, investigators recently interviewed physicians in pediatric and neonatal intensive care concerning end-of-life decision-making. The investigators highlight how different perspectives on best interests could prevail based on the unequal power and authority of physicians, clinical uncertainty, and the complexity of balancing child and family interests [25]. Given the subjective nature of quality of life assessments, physicians should be clear about who is establishing the goals for the child. They should also reflect on their own potential biases and values. Regardless of the physician's certainty regarding outcome, physicians should offer noncoercive recommendations that are informed by the patient's and families' values and that incorporate the interests of the parents, siblings, and family as a whole.

Those recommendations ought not be based exclusively on the physician's values. Listening to the concerns of the family about the "big picture" issues is the key to framing shared decision-making. Such a process takes time and empathy on the part of providers. In an earlier article, we provided a case of an experienced neonatologist who successfully utilized shared decision-making to resolve a potential conflict between the NICU staff and the family [26]. He began by acknowledging the father of a NICU patient was confronted with a nearly unimaginable scenario -his wife, who was pregnant with twins, had undergone an emergency C-Section after one twin's heart rate was no longer detectable. The father, who just lost one daughter and whose wife and second daughter were critically ill, was understandably overwhelmed. This was not an ideal time to ask him to make an important medical decision. Rather what he needed was empathy and above all time to adjust to the new situation. Given the opportunity of support, time and the opportunity of discussion with the attending physician and NICU staff, the father noted that despite this being a much-desired pregnancy neither he nor his wife would want to impose a life of unremitting suffering on their child, or worse, a life without consciousness. The decision to limit further aggressive measures for his daughter became the shared choice of the physician and the 
parents. Here modern medicine was adhering to the wisdom not to attempt medical interventions on a patient "overmastered by disease" [27].

A key aspect of shared decision-making is spending the time to elicit values of the patient's family and culture. Many perceived conflicts are a failure to understand one another. This requires meeting, and meeting, and meeting again, sometimes with other clinicians. But always with curiosity and an openness to understand the parent's point of view. Seemingly obvious, but sometimes elusive, establishing trust remains crucial.

This model of using time to lead to a shared decisionmaking resolution is seen in the case of a compromised newborn with a partial trisomy 16 abnormality [28]. The parents were young, foreign born individuals who insisted the infant was a "normal child." Further the parents believed the medical care was harming their child. Multiple family conferences including a neonatologist, a geneticist, a bioethicist, a social worker, and an interpreter allowed the parents to understand the genetic implications and the staff to understand the family's values. Although initially there was an "ethos of mistrust," after much discussion, the parents eventually proposed a pathway acceptable to them and to the clinicians. The NICU team supported the parents' decision to omit aggressive inpatient medical interventions for their seriously compromised infant and the parents' decision to have the baby go home. The parents understood and accepted that doing so in the United States would require regular nursing visits to the home to support ongoing medical care.

Patient listening to the parents' expectations and values and the careful laying out to the parents of the differing cultural requirements on end-of-life care in the United States from those that prevailed in their native country, convinced the parents that the hospital, the attending physician, and the entire NICU team wanted to do whatever was legally permissible to effectuate the parents' desire to take their infant home. A trusting relationship was established. The parents brought their infant to their home where, after a brief time, the baby no longer required a ventilator or a feeding tube. Once the child was free from the medical machinery, the parents brought him back to the Middle East. Shortly thereafter, he died.

That the parents developed a trusting relationship with the attending physician and the NICU staff is seen in their returning to the medical center for genetic testing to establish that they were not carriers of a genetic abnormality that might impact a future pregnancy. The parents also thanked the attending neonatologist and the nurses for their understanding and support during their child's hospitalization.

The ability to build a trust-filled relationship, which took perseverance and time, ultimately proved helpful in working through a difficult and trying shared decision-making process. Shared decision-making, utilizing the AAP framework, is possible and the most practical means for resolving parental and provider conflicts.

\section{Compliance with ethical standards}

Conflict of interest The authors declare that they have no conflict of interest.

Publisher's note Springer Nature remains neutral with regard to jurisdictional claims in published maps and institutional affiliations.

\section{References}

1. Miller v. HCA, Inc. 118 S.W. 3rd 75. 2003.

2. Annas GJ. Extremely preterm birth and parental authority to refuse treatment-the case of Sidney Miller. N Engl J Med. 2004; 351:2118-23.

3. Paris JJ. From the Johns Hopkins Baby to Baby Miller: what have we learned from four decades of reflection on neonatal cases? J Clin Care Ethics. 2001;12:207-14.

4. Committee on Fetus and Newborn. Noninitiation or withdrawal of intensive care for high risk newborns. Pediatrics. 2007;119:401-3.

5. Kubler-Ross E. On death and dying: what the dying have to teach doctors, nurses, clergy and their own families. New York: Macmillan; 1969.

6. Helft PR, Siegler M, Lantos J. The rise and fall of the futility movement. N Engl J Med. 2000;343:293-6.

7. Schloendorff v. Society of the New York Hospital. 211 N.Y. $125 ; 105$ N.E. 92.1914

8. Matter of Storar, 420 N.E. 2d 64, 52 N.Y. 2d 363, 438 N.Y.S. 2d 266. 1981

9. Weise KL, Okun AL, Carter BS, Christian CW.Committee on Bioethics, Section on Hospice and Palliative Medicine, Committee on Child Abuse and Neglect Guidance on forgoing lifesustaining medical treatment. Pediatrics. 2017;140:e2017905

10. Maine Medical Center v. Baby Boy Houle. No. 74-145. Cumberland City, ME: Super. Ct.; 1974.

11. McCormick RA. To save or let die? The dilemma of modern medicine. JAMA. 1974;229:172-6.

12. Berlinger N, Jennings B, Wolf SM. The Hastings Center Guidelines on life sustaining-treatment and care near the end of life. 2nd ed. Oxford: Oxford University Press, 2013.

13. Duff RS, Campbell AGM. Moral and ethical dilemmas in the special care nursery. N Engl J Med. 1973;289:890-4.

14. Paris JJ, McCormack RA. Saving Defective infants: options for life or death. Am Mag. 1983;148:313-7.

15. Paris JJ, Cummings BM, Moore MP. "Brain death," "dead," and parental denial: the case of Jahi McMath. Camb Q Health Ethics. 2014;23:371-82.

16. Stinson R, Stinson P. The long dying of baby Andrew. Boston: Little Brown and Company; 1983.

17. Paris JJ, Anhulawalia J, Cummings BM, Moreland MP, Wilkinson DJ. The Charlie Gard case: British and American approaches to court resolution of disputes over medical decisions. J Perinatol. 2017;37:1268-77.

18. Caplan A, McCartney J, Sisti DA. The case of Terri Schiavo: ethics at the end of life. Amherst, NY: Prometheus Books; 2006.

19. Clark K. Alfie's last days: a little boy's life and death stoked a furious debate that will not soon end. Am Mag. 2018. https://www.americamagazine.org/politics-society/2018/04/26/a lfies-last-days-little-boys-life-and-death-stoked-furious-debate-w ill. Accessed March 21, 2020. 
20. Lantos JD. Ethical problems in decision making in the neonatal ICU. N Engl J Med. 2018;379:1851-60.

21. Cummings BM, Paris JJ, Batten JN, Moreland MP. Disputes between physicians and family on surgical treatment for an infant with ultra short gut syndrome: the perspectives of an Ethics Committee. J Perinatol. 2018;38:781-4.

22. Cummings BM, Paris JJ. Conjoined twins separation leading to the death of one twin: an expanded ethical analysis of issues facing the ICU team. J Intensive Care Med. 2018;20:1-5.

23. Soltys F, Philpott-Streiff SE, Fuzzell L, Politi MC. The importance of shared decision-making in the neonatal intensive care unit. J Perinatol. 2019. https://doi.org/10.1038/s41372-019-0507-6.

24. Weiss EM, Xie D, Cook N, Coughlin K, Joffe S. Characteristics associated with preferences for parent-centered decision making in neonatal intensive care. JAMA Pediatr. 2018; 172:461-8.

25. Richards CA, Starks H, O'Connor MR, Bourget E, Hays RM, Doorenbos AZ. Physicians perceptions of shared decision-making in neonatal and pediatric critical care. Am J Hosp Palliat Care. 2018;35:669-76.

26. Paris JJ, Pai V, Cummings BM, Batten JN, Benitz WE. Approaches to end-of-life discussions with parents of a profoundly compromised newborn. J Perinatol. 2017;37:1078-81.

27. Jones WHS, editors. Hippocrates II. Cambridge, MA: Harvard University Press; 1923. p. 193.

28. Penn AA, Paris JJ, Moore MP. Decision making for seriously compromised newborns: the importance of explaining cultural differences and unanticipated consequences. J Perinatol. 2013;33:505-8. 